\title{
Intergenerational mobility in Korea
}

\author{
Soobin Kim (1)
}

\section{Correspondence:}

soobinki@msu.edu

College of Education, Michigan

State University, 620 Farm Lane,

Room 516, Erickson Hall, East

Lansing, MI 48824-1038, USA

\section{Introduction}

Intergenerational mobility refers to the persistence between parents' and children's outcomes. If parents' earnings do not impact much on their offspring's earnings, the degree of intergenerational earnings mobility is high, and it could be that relative economic disadvantages in the early years will persist to a lower extent in adulthood. That is, intergenerational earnings mobility explores the characteristics of inequality in economic opportunity as well. For a survey of relevant literature, see Solon (1999) and Black and Devereux (2010).

Some features of Korea make it an interesting case for the study of intergenerational mobility. First, Korea experienced rapid and extensive economic growth in the past half century when the real GDP per capita increased 15-fold. At the same time, inequality in labor earnings steadily decreased from the 1970s to the 1990s. The extent to which these changes in labor market conditions is related to the high degree of intergenerational mobility is an interesting question. Second, the Korean education system is very competitive due to the strong desire of Koreans for education, and Korea went through a great expansion in education in the last few decades. At the same time, education has been viewed as a vehicle to the next highest level of schooling and a means of obtaining higher socio-economic status (Korea 1991). Thus, whether the intergenerational mobility varies with parental education is another relevant question to answer.

Because of a lack of longitudinal data spanning two generations, only a limited number of studies on intergenerational earnings mobility in Korea have been done. Recent studies in Korea by Kim (2009) and Choi and Hong (2011) employed co-residing father-son pairs

(c) The Author(s). 2017 Open Access This article is distributed under the terms of the Creative Commons Attribution 4.0 International License (http://creativecommons.org/licenses/by/4.0/), which permits unrestricted use, distribution, and reproduction in any medium, provided you give appropriate credit to the original author(s) and the source, provide a link to the Creative Commons license, and indicate if changes were made. 
in the initial round of panel data. However, as noted by Solon (2002), this sample may display a different intergenerational association than would a more representative sample. ${ }^{1}$ Moreover, as in most other empirical studies, they estimated intergenerational earnings elasticities using short-run proxies for permanent earnings, which may generate downward biases in estimates. ${ }^{2}$ An important exception avoiding this difficulty is Ueda (2013) who utilized a two-sample method to impute fathers' permanent earnings and showed relatively higher estimated intergenerational earnings mobility in Korea.

This study estimates intergenerational earnings mobility in Korea following the method presented in Ueda (2013) and extends empirical analysis in two dimensions. First, I use an additional national representative sample to better approximate the actual fathers' birth cohorts so that fathers' missing permanent earnings are more accurately imputed. I also carefully choose age ranges for each generation to minimize life-cycle bias that stems from using current earnings for lifetime earnings. ${ }^{3}$ Second, I compare the intergenerational mobility of Korea with that of 13 other countries that come from the two-sample method. The intergenerational elasticity estimate of around 0.4 in Korea is similar to that in already developed countries and relatively smaller than recently developed or developing countries.

The remainder of this study is organized as follows: Section 2 describes the methodology employed in early literature. Section 3 discusses the data. Section 4 presents the empirical results. Section 5 concludes with remarks.

\section{Literature review and method}

In this section, I provide a skeletal derivation of the intergenerational mobility developed in Solon (1992) and Björklund and Jäntti (1997). The basic empirical approach in intergenerational mobility literature is to estimate earnings elasticity, which is to estimate $\rho_{1}$ in the following equation.

$$
y_{i}=\rho_{0}+\rho_{1} x_{i}+\epsilon_{i}
$$

where $y_{i}$ is the log of the permanent component of the son's earnings in family $i, x_{i}$ is the $\log$ of the permanent component of the father's earnings in family $i$, and $\epsilon_{i}$ is a random disturbance uncorrelated with $x_{i}$. If $y_{i}$ and $x_{i}$ are observed directly from a random sample, one can estimate $\rho_{1}$ in Eq. (1) by applying least squares regression. Here the parameter $\rho_{1}$ is the intergenerational earnings elasticity and $\left(1-\rho_{1}\right)$ can be interpreted as a measure of intergenerational mobility. Therefore, by comparing $\hat{\rho}_{1}$ of each country, comparisons of intergenerational mobility across countries are possible; the higher $\hat{\rho}_{1}$ is, the less mobile the society is. ${ }^{4}$

However, in most studies, available measures of the earnings variable are current earnings in repeated cross-section samples or in longitudinal samples, and in practice, researchers have used short-run proxies of $y_{i t}$ for long-run economic status variables of $y_{i}$ in time $t$,

$$
y_{i t}=\lambda_{t} y_{i}+h\left(\mathrm{Age}_{i t}\right)+v_{i t}
$$

where $\lambda_{t}$ is the association between current and lifetime earnings at time $t$, which is allowed to vary over the life cycle, and $v_{i t}$, the measurement error in $y_{i t}$ as a proxy for $y_{i}$, is assumed to be uncorrelated with $y_{i}$ and $\epsilon_{i} . h\left(\mathrm{Age}_{i t}\right)$ is an arbitrary function of a son's age at time $t$ such as a polynomial in age. 
If one has an appropriate measure of a father's long-run earnings but is forced to use current earnings as a proxy for the son's long-run earnings, plugging Eq. (1) into Eq. (2) yields

$$
y_{i t}=\lambda_{t} \rho_{0}+\lambda_{t} \rho_{1} x_{i}+h\left(\text { Age }_{i t}\right)+\eta_{i t}
$$

where $\eta_{i t}$ is equal to $\lambda_{t} \epsilon_{i}+v_{i t}$. In addition to the measurement error in lifetime earnings, Haider and Solon (2006) and Grawe (2006) presented empirical evidence of another source of inconsistency that short-run earnings deviate from long-run earnings over the life cycle: The probability limit of the least squares estimator of the coefficient of $x_{i}$ is equal to $\lambda_{t} \rho_{1}$. Haider and Solon (2006) suggested the age ranges be used for both father and son around their mid-careers, which would more accurately represent lifetime earnings. ${ }^{5}$

Another estimation problem exists when a single dataset containing earnings data for pairs of fathers and sons in a long-time series is unavailable. Björklund and Jäntti (1997) proposed a two-sample method to impute fathers' missing earnings from an auxiliary sample of a father's generation on the basis of a son's report on a father, such as education, industry, and occupation. ${ }^{6}$ Let $z_{i}$ denote a set of fathers' socio-demographic variables such as education and occupation and assume that the permanent component of fathers' earnings is generated by the following relationship:

$$
x_{i}=z_{i} \phi+\xi_{i}
$$

where $z_{i}$ is orthogonal to $\xi_{i}$ by linear projection. From Eq. (4), fathers' long-run economic status variables are generated, $\hat{x}_{i}=z_{i} \hat{\phi}$, with age controls in the potential fathers' sample. ${ }^{7}$

Rewrite Eq. (1) as $y_{i}=\rho_{0}+\rho_{1} \hat{x}_{i}+\epsilon_{i}+\rho_{1}\left(x_{i}-\hat{x}_{i}\right)$ and plug into Eq. (2) gives

$$
y_{i t}=\lambda_{t} \rho_{0}+\lambda_{t} \rho_{1} \hat{x}_{i}+h\left(\operatorname{Age}_{i t}\right)+\omega_{i t}
$$

where $\omega_{i t}$ is equal to $\lambda_{t} \epsilon_{i}+v_{i t}+\lambda_{t} \rho_{1}\left(x_{i}-\hat{x}_{i}\right)$. Under regularity conditions described in the Appendix, the probability limit of the least squares estimator of the coefficient of $x_{i}$ is equal to

$$
\operatorname{plim}_{n \rightarrow \infty} \hat{\rho}_{1}=\frac{\lambda_{t} \rho_{1} \operatorname{Var}\left(x_{i}\right)+\operatorname{Cov}\left(x_{i}, v_{i t}\right)}{\operatorname{Var}\left(x_{i}\right)}
$$

which reduces to $\lambda_{t} \rho_{1}$ if $\operatorname{Cov}\left(x_{i}, v_{i t}\right)=0$. (The proof can be reviewed in the Appendix). However, the consistency still depends on $\lambda_{t}$ even with the generated regressor, and it calls for researcher caution in choosing the appropriate age range as Haider and Solon (2006) proposed. Nybom and Stuhler (2016) used long series of Swedish income data that contain nearly complete income histories of both fathers and sons and verified Haider and Solon's implications that the life-cycle bias is smallest when incomes are observed around midlife and that the life-cycle bias cannot be eliminated at other ages. ${ }^{8}$ Finally, ordinary least squares regression is applied to Eq. (5) to estimate $\rho_{1} \cdot{ }^{9}$

Generally, most studies with this methodology have two datasets: The first provides sons' economic status variables with sons' recollected information of fathers' education, industry, and occupational characteristics at the son's particular age during childhood. Those variables are used to generate fathers' missing economic status variables. The second dataset contains potential fathers' economic status variables with socio-demographic characteristics. This supplementary sample is used to predict fathers' economic status variables like earnings, based on fathers' socio-demographic characteristics when sons 
were at a specific age as reported in the first dataset. Then $\rho_{1}$ can be estimated from Eq. (5) with predicted fathers' earnings, $\hat{x}_{i}$, in lieu of fathers' permanent earnings, $x_{i}$.

Similar to many other countries, Korea does not have a sufficiently long intergenerational panel dataset where explicit information of father-son pairs' economic status variables are observed. Several studies in Korea were done by employing the Korean Labor and Income Panel Study (KLIPS). Using KLIPS, Kim (2009) and Choi and Hong (2011) focused on father-son pairs who co-resided in 1998 and restricted sons who in subsequent years moved into a non-member household (for instance, through marrying). This homogeneous sample of co-resident father-son pairs is an endogenously selected sample and would demonstrate an intergenerational transmission of earnings different from the population. They averaged available earnings to overcome attenuation bias because current earnings are proxied for permanent earnings. However, including younger sons-around 30 - and older fathers-in the late 50s-tends to lower estimates due to life-cycle bias. For monthly earnings, coefficients are $0.141(0.042)$ and $0.349(0.096)$ when the father's education is instrumented for the father's earnings.

Ueda (2013) also used KLIPS to estimate intergenerational mobility in Korea and employed a two-sample method to impute actual fathers' permanent earnings using sons' recollections of their fathers' educational levels and occupations when they were 14 . Among working men with positive wages aged 25-54 for fathers and 30-39 for sons, Ueda restricted the sons' sample to 2006 and pooled annual earnings for the potential fathers' sample observed over the period 2003-2006. The coefficient is 0.223 (0.072), but Ueda imputed a too-recent earnings function instead of choosing the fathers' sample in actual calendar time.

\section{Data}

KLIPS contains sons' earnings and their recollections of fathers when they were 14 and is the first Korean longitudinal survey on the labor market and income activities of households and individuals, collected from 1998 to 2008. During the first wave in 1998, a representative sample of 5000 households and their members (15 and over), covering more than 13,000 individuals, was interviewed using the sampling frame from the census, and they became the original panel of households and household members.

In addition, Household Income and Expenditure Survey (HIES) is repeated crosssection survey data that are the only publicly available data at an individual level with economic status variables such as labor earnings, family income information of each household, and socio-demographic characteristics. Survey data are available since 1982; however, education information was added to the survey since 1985. HIES, as in KLIPS, used the sampling frame of the census, which supports the argument that both datasets are representative samples of the Korean labor market.

Monthly labor earnings are recorded pre-tax in HIES and net of taxes in KLIPS. The pre-tax labor earnings in KLIPS can be calculated because tax on labor earnings is also available in KLIPS from 2004. One data limitation of KLIPS is that the income of self-employed workers is recorded by after-tax value whereas HIES does not provide income information for self-employed workers. This renders it harder to estimate accurate mobility when self-employed fathers are included. ${ }^{10}$ In this study, labor earnings are the main focus, because most previous studies used earnings and it enables international comparison of intergenerational mobility. In addition, earnings mobility is better 
suited to measure mobility based on an individual's merit than do other economic status variables. ${ }^{11}$

KLIPS and HIES have recorded education, occupation, and industry in different categories. Especially occupation and industry variables are recorded with three digits in KLIPS, but in one digit and two digits in HIES, respectively. Since the categories used for industry and occupation in KLIPS are finer than those used in HIES, those variables are matched according to the HIES category. After recoding categories to have a homogeneous classification across samples, seven different levels of education, nine industry groups, and seven occupational groups are available to predict fathers' missing earnings. The number of predictors for fathers' missing earnings as well as the number of groups of each variable are relatively richer than in previous studies in other countries. ${ }^{12}$

In the analysis, I use two waves of KLIPS for the sons' sample and both KLIPS and HIES for the potential fathers' sample. When replicating Ueda's empirical results, I use KLIPS in 2006 for the sons' sample and KLIPS in 2003 for the potential fathers' sample. Since the age gap between sons in KLIPS in 2006 and potential fathers in KLIPS in 2003 is three, to use more approximal cohorts of actual fathers, I retrieve the sons' sample from KLIPS in 2008 and the potential fathers' sample from HIES in 1985. These two samples are 23 years apart which thus enables matching of the father's generation more closely to actual fathers than does using 2003 for the potential fathers' sample. ${ }^{13}$

Preferred age range for both generations is between 35 and 50 as the errors-in-variables bias in sons' earnings stays small, modifying the results from Haider and Solon (2006) given that Korean male workers generally enter the labor market about 3-5 years later than in the USA due to mandatory military service obligations. ${ }^{14}$

Both KLIPS in 2008 and HIES in 1985 are restricted to working men aged between 35 and 50 with positive wages, which leaves 1700 observations in KLIPS and 1780 in HIES. ${ }^{15}$ Especially in HIES, the fathers' sample was further restricted to those with a positive number of children aged 6-19 in 1985. Fathers or sons who lived in foreign countries when their sons were 14 are excluded. Narrowing the sample to those with all education, industry, and occupation variables recorded, the number of observation drops to 1666 in KLIPS and 1577 in HIES. Descriptive statistics of variables used for the main sample and the supplemental sample are summarized in Table 1.

\section{Empirical results}

To extend the empirical results from Ueda (2013), the analysis starts by following his identification strategy of applying the two-step method to a single dataset, KLIPS, and introduces HIES for the potential fathers' sample. Ueda (2013) averaged annual earnings between 2003 and 2006 for potential fathers and retrieved sons' earnings from 2006 and restricted ages for sons to $30-39$ and for fathers to $25-54$. To provide results similar to Ueda, I retrieve sons' earnings from KLIPS in 2006 and potential fathers' annual earnings from 2003 and restrict the same age ranges for sons and fathers. To implement the twosample method, in the first step in Eq. (4), fathers' log earnings in 2003 are regressed on age, age-squared, industry, occupation, and education variables followed by sample selection rules described in the previous section. Then, as in Eq. (5), sons' log earnings in 2006 from KLIPS are regressed on generated fathers' permanent earnings, age, and age squared of sons. ${ }^{16}$ Standard errors are estimated by the bootstrap method following Björklund and Jäntti (1997). ${ }^{17}$ Table 2 summarizes results and the estimate replicating Ueda's approach 
Table 1 Descriptive statistics

\begin{tabular}{|c|c|c|c|}
\hline & Actual fathers & $\begin{array}{l}\text { Potential fathers described } \\
\text { by sons }\end{array}$ & Sons in HIES \\
\hline Mean age & 41 & & 41 \\
\hline \multicolumn{4}{|l|}{ Education } \\
\hline None & 6.9 & 1.7 & 0.2 \\
\hline Elementary & 26.1 & 15.4 & 1.8 \\
\hline Middle & 20.8 & 23.7 & 4.1 \\
\hline High & 29.2 & 34.8 & 30.6 \\
\hline Community college (2 years) & 2.0 & 2.4 & 18.2 \\
\hline University (4 years) & 13.7 & 20.4 & 34.3 \\
\hline Graduate school & 1.4 & 1.7 & 10.8 \\
\hline \multicolumn{4}{|l|}{ Occupation } \\
\hline Professional, technical, managerial & 12.7 & 8.1 & 36.5 \\
\hline High-rank government officer, entrepreneur & 2.6 & 0.7 & 2.6 \\
\hline Administrative worker & 16.7 & 24.9 & 19.2 \\
\hline Office worker & 5.2 & 7.7 & 3.7 \\
\hline Service worker & 3.2 & 5.3 & 3.5 \\
\hline Production worker & 37.4 & 51.1 & 33.3 \\
\hline Agriculture, fishing, forestry & 22.3 & 2.2 & 1.2 \\
\hline \multicolumn{4}{|l|}{ Industry } \\
\hline Agriculture, fishing, forestry & 12.1 & 2.0 & 0.6 \\
\hline Mining & 2.4 & 1.5 & 0.0 \\
\hline Manufacturing & 18.2 & 30.3 & 28.6 \\
\hline Utilities & 0.2 & 1.1 & 1.4 \\
\hline Construction & 19.6 & 18.0 & 12.6 \\
\hline Wholesale and retail trade & 10.3 & 8.8 & 11.6 \\
\hline Communication, transportation & 8.9 & 12.3 & 7.7 \\
\hline Banking, business service & 5.0 & 4.1 & 17.8 \\
\hline Public administration, education & 23.4 & 22.0 & 19.8 \\
\hline
\end{tabular}

Note: Age of father-son sample is restricted to 35-50

Table 2 Intergenerational earnings elasticity

\begin{tabular}{|c|c|c|c|c|}
\hline Sons' age & Fathers' age & Sample size & $\hat{\rho}_{1}$ & Std. err \\
\hline \multicolumn{5}{|c|}{ Panel A: original from Ueda } \\
\hline $30-39$ & $25-54$ & 809 & $0.223^{* * *}$ & 0.072 \\
\hline \multicolumn{5}{|c|}{ Panel B: replication of Ueda using KLIPS2006 } \\
\hline $30-39$ & $25-54$ & 1142 & $0.205^{* * *}$ & 0.057 \\
\hline \multicolumn{5}{|c|}{ Panel C: replication of Ueda using KLIPS2008 } \\
\hline $30-39$ & $25-54$ & 1083 & $0.310^{* * *}$ & 0.060 \\
\hline \multicolumn{5}{|c|}{ Panel D: role of age } \\
\hline $35-50$ & $25-54$ & 1666 & $0.307^{* * *}$ & 0.054 \\
\hline $35-50$ & $35-50$ & 1666 & $0.334^{* * *}$ & 0.057 \\
\hline \multicolumn{5}{|c|}{ Panel E: employed fathers } \\
\hline $35-50$ & $35-50$ & 675 & $0.218^{* * *}$ & 0.061 \\
\hline \multicolumn{5}{|c|}{ Panel F: self-employed fathers } \\
\hline $35-50$ & $35-50$ & 991 & $0.144^{*}$ & 0.083 \\
\hline \multicolumn{5}{|c|}{ Panel G: potential fathers from HIES } \\
\hline $35-50$ & $35-50$ & 675 & $0.386^{* * *}$ & 0.064 \\
\hline
\end{tabular}

Notes: Sons' information is retrieved from KLIPS 2006 for panels A-B and from KLIPS 2008 for panels C-G. Potential fathers' information is retrieved from KLIPS 2003 for panels A-F and from HIES 1985 for panel G. Bootstrapped standard errors are in parentheses

"Significant at the $10 \%$ level; ***Significant at the $1 \%$ level 
is 0.205 with a bootstrapped standard error of 0.057 , which is similar to Ueda's baseline estimate of 0.223 . Ueda used education and occupation to predict fathers' missing earnings, and when I use those two variables as predictors, the estimate is $0.244(0.094)$. When the later round in 2008 is used for the sons' sample, the estimate is $0.310(0.060)$ which suggests that detailed matching of potential fathers with actual fathers could be important.

Restricting to the preferred age range of $35-50$ for both generations, the estimate in panel D increases to 0.334 (0.057), partly due to excluding young fathers. Results are consistent with previous studies on life-cycle bias; inclusion of younger sons or older fathers lowers estimates. That is, the correlation between a father's age (son's age) at measurement and the size of $\hat{\rho}_{1}$ is negative (positive). The next two panels examine whether the elasticity is different with respect to the father's self-employment status. Nine hundred and ninety-one out of 1666 sons have self-employed fathers when they were 14, and the estimates are 0.144 (0.083) for sons with self-employed fathers and $0.218(0.061)$ for sons with employed fathers, which frees concern that the self-employment status of fathers might significantly affect the estimates.

Approximating pseudo-fathers' earnings with recent cohorts, however, implicitly assumes that potential fathers' characteristics in 2003 are close to those for actual fathers, and uses information from the younger-father generation. In other words, if the average age gap between fathers and sons is 30 , then fathers' actual ages in 2003, whose sons are aged 30-39 in 2008, are 55-64 instead of 25-54. Moreover, occupation, industry, and education distribution in 2003, used for potential fathers' characteristics, are more similar to those for sons in 2008 than to those for actual fathers. Thus, results of this approach are vulnerable if one supposes significant changes occurred in the wage structure in recent decades. To retrieve potential fathers' information from a more approximal cohort of actual fathers, I use HIES and generate pseudo-fathers' earnings based on sons' recollections on fathers' characteristics.

\subsection{The role of HIES}

By retrieving potential fathers' information from HIES in 1985, the father-son age gap becomes more realistic and the distribution of earnings predictors including education, occupation, and industry becomes closer to those of actual fathers remembered by sons than to those of potential fathers in KLIPS 2003.

Age ranges for both generations are restricted to $35-50$ as it best reflects the feature of the Korean labor market that mandatory military service generally delays men from joining it. Moreover, the preferred age range better represents mid-career earnings, and this specification with three earnings predictors for fathers is served as the baseline model. ${ }^{18}$ By excluding younger sons in their later 20 s and early 30 s and older fathers above 50, the estimate increases to 0.386 (0.064) in panel G in Table $2 .{ }^{19}$

Table 3 further reports regression results with several different sample specifications. Some concern might arise that the occupation distribution of potential fathers and real fathers are imperfectly matched. Although required information from the first step is the sample average of earnings in each predictor category, in panel A, the occupation categories are merged and reorganized to generate similar distributions. However, the number of categories does not change estimates significantly. In fact, estimates lie in the range 
Table 3 Sensitivity of intergenerational earnings elasticity

\begin{tabular}{|c|c|c|c|}
\hline & Sample size & $\hat{\rho}_{1}$ & Std. err \\
\hline Baseline & 675 & $0.386^{* * *}$ & 0.059 \\
\hline \multicolumn{4}{|c|}{ Panel A: role of occupation category } \\
\hline \multicolumn{4}{|c|}{ Occupation category } \\
\hline 6 & 675 & $0.401^{* * *}$ & 0.062 \\
\hline 5 & 675 & $0.407^{* * *}$ & 0.061 \\
\hline 4 & 675 & $0.405^{* * *}$ & 0.061 \\
\hline \multicolumn{4}{|c|}{ Panel B: role of averaging for balanced sample } \\
\hline \multicolumn{4}{|l|}{ Period } \\
\hline $2007-2008$ & 483 & $0.426^{* * *}$ & 0.058 \\
\hline $2006-2008$ & 459 & $0.445^{* * *}$ & 0.057 \\
\hline $2005-2008$ & 410 & $0.471^{* * *}$ & 0.060 \\
\hline \multicolumn{4}{|c|}{ Panel C: predictor combination } \\
\hline \multicolumn{4}{|c|}{ Predictor } \\
\hline Industry & 678 & $0.585^{* * *}$ & 0.105 \\
\hline Occupation & 675 & $0.398^{* * *}$ & 0.074 \\
\hline Education & 684 & $0.354^{* * *}$ & 0.076 \\
\hline Ind and occ & 675 & $0.411^{* * *}$ & 0.063 \\
\hline Occ and edu & 675 & $0.392^{* * *}$ & 0.065 \\
\hline Ind and edu & 678 & $0.394^{* * *}$ & 0.065 \\
\hline Ind and occ and edu & 675 & $0.386^{* * *}$ & 0.059 \\
\hline
\end{tabular}

0.401 to 0.407 when the number of occupation categories is changed from 6 to 4 , which indicates that the estimates are robust to occupation specifications. Thus, a different occupation category distribution has negligible impact on estimates.

The age range of 35-50 is chosen to have $\lambda_{t}$ close to 1 so that the measurement error is close to the classical errors-in-variables. Many studies using current earnings to proxy for permanent earnings averaged earnings over years to deal with the measurement error following Solon (1992). Estimates of intergenerational earnings elasticity become larger as fathers' earnings are averaged over more years. As potential fathers are taken from HIES in 1985 and HIES is repeated cross-section data, calculating missing father's average earnings is challenging. In addition, Nybom and Stuhler (2016) provided evidence that changing the age span for sons has more impact on life-cycle bias than changing that of fathers. Thus, sons' earnings are averaged over years, and the results in panel B show that the estimates increase as earnings are averaged over more years.

In the base model, all three earnings predictors are used. If one changes the combination of earnings predictors and uses a subset of predictors, sample size increases by only nine, which frees the concern of having a smaller sample size in exchange for having more predictors. Results in panel $\mathrm{C}$ indicate that the estimates change from 0.35 to 0.59 , suggesting that researchers should pay attention when they choose appropriate predictors. Equation (6) implies that the estimator with a generated regressor is inconsistent if father's earnings predictors are correlated with son's earnings $\left(\operatorname{Cov}\left(x_{i}, v_{i t}\right)=0\right)$. For example, if the father's education has a positive effect on son's earnings, then the estimator may be upward biased. However, the extent to which other predictors such as 
father's industry or occupation are correlated with son's earnings is less clear and so is the direction of bias. In addition, first-stage results from Table 4 show that the industry variable explains relatively less variations in earnings than occupation or education does, which could result in a higher $\hat{\rho}_{1}$ of 0.59 . On the other hand, all other estimates that used father's education as a predictor are close to 0.39 . For comparison, majority of other countries' studies on intergenerational elasticity with two-sample estimation, documented in Table 5, did not use an industry variable to predict fathers' earnings. However, it is not clear in which direction the estimate would move if an industry variable is included. ${ }^{20}$

\subsection{International comparison}

Table 5 summarizes the evidence of intergenerational mobility from 13 other countries that come from two-sample estimation. For comparability with the Korea results, the table focuses on the earnings elasticity estimates of father-son pairs and lists the age ranges and sets of predictors used to generate fathers' earnings. While Nybom and Stuhler (2016) pointed out that the bias in elasticity estimates can differ across countries and cohort even if earnings are measured at the same age, we might expect similarities in its broad patterns. The intergenerational elasticity estimate around 0.4 in Korea is similar to that of already developed countries and relatively smaller than recently developed or developing countries. That is, the mobility in Korea is relatively higher than other developing countries (e.g., 0.69 in Brazil and 0.52 in Chile) ${ }^{21}$

Some studies, for instance Piraino (2007) in Italy, investigated the channels in the transmission of economic status and found parental education's contribution to the intergenerational mobility. Korea went through a great expansion in education in the last few decades, and the parent-child schooling correlation among 20-69 sons in 2008 is only 0.333 , one of the lowest values according to Hertz et al. (2008). ${ }^{22}$ In particular, approximately $60 \%$ of sons in 2008 are educated beyond high schools, whereas about $50 \%$ of their fathers have education equal or less than middle school. At the same time, there is a differential probability of attaining post-secondary education degree by father's status. For example, the probability of attaining college or advanced degree is 32 percentage points higher for sons whose fathers are educated more than middle school. As the wage gap between sons with a college or advanced degree and those with no education beyond high school is $100 \%$ in 2008, I estimate the role of education as a channel of intergenerational transmission by adding the son's education dummy variables to Eq. (5). The resulting $\hat{\rho}_{1}=0.196$ suggests that education explains $49 \%$ of the observed persistence, which is

Table 4 Choice of father's earnings predictors

\begin{tabular}{llllll}
\hline Case & Earnings predictors & $F$ & $R^{2}$ & Adj $R^{2}$ & Root MSE \\
\hline 1 & Industry & 24.61 & 0.137 & 0.132 & 0.499 \\
2 & Occupation & 80.22 & 0.293 & 0.289 & 0.451 \\
3 & Education & 99.15 & 0.339 & 0.335 & 0.436 \\
4 & Ind and occ & 47.26 & 0.329 & 0.322 & 0.441 \\
5 & Occ and edu & 66.64 & 0.377 & 0.371 & 0.424 \\
6 & Ind and edu & 56.26 & 0.369 & 0.362 & 0.427 \\
7 & Ind and occ and edu & 46.77 & 0.402 & 0.393 & 0.417 \\
\hline
\end{tabular}

Note: Age of father-son sample is restricted to $35-50$ 
Table 5 Comparable intergenerational earnings elasticity with two-sample estimation

\begin{tabular}{lllllll}
\hline Country & Authors & $\hat{\rho}_{1}$ & Std. err & Age $^{f}$ & Age $^{s}$ & Earnings predictors \\
\hline Australia & Leigh (2007) & 0.41 & 0.137 & $25-54$ & $25-54$ & Occ \\
Brazil & Dunn (2007) & 0.69 & 0.014 & $30-50$ & $25-34$ & Edu \\
Canada & Fortin and Lefebvre (1998) & 0.22 & 0.051 & $40-50$ & $17-59$ & Occ \\
Chile & Núñez and Miranda (2011) & 0.52 & N.A. & N.A. & $23-65$ & Edu, occ \\
China & Gong et al. (2012) & 0.63 & 0.117 & $48-74$ & $30-42$ & Edu, occ, ind \\
France & Lefranc (2011) & 0.50 & 0.028 & $25-60$ & $28-50$ & Edu \\
Italy & Piraino (2007) & 0.44 & 0.053 & $30-50$ & $27-49$ & Edu, occ, ind \\
Italy & Mocetti (2007) & 0.49 & 0.069 & $30-50$ & $30-50$ & Edu, occ, ind, region \\
Japan & Lefranc et al. (2014) & 0.34 & 0.042 & $30-59$ & $30-50$ & Edu, occ, ind \\
Spain & Cervini-Plá M (2013) & 0.40 & 0.042 & $37-57$ & $30-50$ & Edu, occ \\
Sweden & Björklund and Jäntti (1997) & 0.28 & 0.094 & 43 & $30-39$ & Edu, occ \\
Taiwan & Ueda and Sun (2012) & 0.21 & 0.060 & $30-59$ & $30-49$ & Edu, occ \\
UK & Nicoletti and Ermisch (2008) & 0.29 & 0.061 & $31-55$ & $30-45$ & Edu, occ \\
USA & Björklund and Jäntti (1997) & 0.42 & 0.121 & N.A. & $28-36$ & Edu, occ \\
\hline
\end{tabular}

Notes: Leigh (2007) used predicted hourly wage for a 40-year-old, and the estimates in the table show results with the 1987 sample. When the 2004 sample is used, the estimate is 0.18 with standard errors of 0.043 . Fortin and Lefebvre (1998) assumed a 25-35-year difference between father and son. Björklund and Jäntti (1997) used the mean age of 43

N.A. not applicable

similar to the previous findings in the USA (Bowles and Gintis 2002; Blanden et al. 2014). Additional analysis shows that intergenerational mobility differs with respect to father's education. In particular, sons whose fathers have an education equal or less than middle school have the highest intergenerational elasticity estimate of 0.415 . On the contrary, the elasticity estimate for sons whose fathers have a high school degree is 0.252 . Finally, the estimate for sons whose fathers have a college or more advanced degree is 0.193 , which indicates the highest intergenerational earnings mobility. The extent to which the differential intergenerational mobility by the father's education translates into the earnings inequality is important for future research.

\section{Remarks}

This study examines intergenerational earnings mobility in Korea with the two-sample estimation method to generate the father's missing permanent earnings by combining a panel dataset, which includes the son's earnings and recollection information on the father's socio-demographic characteristics, and a cross-section dataset, which contains earnings and socio-demographic information of potential fathers. Results indicate that the measurement error in sons' current earnings as a proxy for permanent earnings is a source of inconsistency even when fathers' earnings are generated. Thus, the working father-son sample is restricted to age 35-50 to be least affected by the life-cycle bias, and the elasticity estimate is around 0.4. Estimated intergenerational earnings elasticity is similar to estimates for some already developed countries and smaller than typical estimates for recently developing countries.

Previous studies on Korean intergenerational earnings elasticity tend to have lower estimates than 0.4. Some included younger sons and older fathers in the sample, and those factors contributed to lower estimates. Moreover, focusing on a homogeneous sample of co-residing father-son pairs may result in lower estimates. Ueda (2013) also employed two-sample estimation; however, less attention was paid to detailed matching, as an 
inaccurate period of observation for the potential fathers' sample was used for imputation. $^{23}$ Thus, this study contributes to more acute estimation of mobility, with two representative samples aiming to match pairs correctly by choosing the right age range for both generations, which better represents permanent earnings.

Perhaps one of the most important remaining issues to deal with is the life-cycle bias in Korea. As Nybom and Stuhler (2016) suggested, life-cycle bias will differ quantitatively across countries and cohorts, and small age deviations can cause notable changes in elasticity estimates, which appears to be relevant in the Korean context. For example, male workers in Korea generally have to serve in the army from their late teens, which on average delays labor market participation timing by 3 to 5 years compared to the USA. Since data access to individual earnings histories for multiple generations is limited in Korea, instead of analyzing the framework as in Haider and Solon (2006) or in Nybom and Stuhler (2016), alternative approaches to studying the life-cycle bias in Korea are required in the future.

\section{Endnotes}

${ }^{1}$ In fact, they further restricted the sample to those sons who moved out to form a new household. This sample selection approach has a potential risk of endogenous sample selection; non-co-residence sons during certain birth years are out of the sample and the way they moved out is endogenous. Moreover, if the average son's age in the sample is older than the average or median home-living son's age, then the sample over-represents sons who left home at late ages. Francesconi and Nicoletti (2006) in the UK found a downward bias of up to $25 \%$ in intergenerational elasticity when the sample is restricted to co-residence father-son pairs.

${ }^{2}$ See Solon (1992) for details.

${ }^{3}$ Earnings vary with observed age, and a life-cycle pattern exists in the correlation between current observed and lifetime earnings, known as life-cycle bias. Studies showed estimates to be sensitive to not only the father's observed age but also the son's age. If, for instance, the son's earnings are observed in the early stage of his career, it causes a downward effect on the estimate. Theoretical and empirical analyses of life-cycle bias are well documented in the USA by Haider and Solon (2006), in Sweden by Böhlmark and Lindquist (2006) and by Nybom and Stuhler (2016), and in Germany by Brenner (2010). The evidence from these studies shows that income measures in the age range between the early-30s and the mid-40s should be least affected by life-cycle bias when dependent variables are proxied. There is no study of life-cycle bias for any Asian countries nor for generated regressors, yet I adopted their results and modified them based on Korean labor market features.

${ }^{4}$ An alternative way to measure the extent of intergenerational earnings mobility is to estimate intergenerational correlation, $\kappa$.

$$
\kappa=\left(\sigma_{0} / \sigma_{1}\right) \rho_{1}
$$

where $\sigma_{1}$ is the standard deviation of a son's log earnings and $\sigma_{0}$ is the same variable for his father. By construction, $\kappa$ is equal to $\rho_{1}$ only if the standard deviations of log earnings are the same for both generations. 
${ }^{5}$ In a classical errors-in-variables model when $\lambda_{t}=1$, the OLS estimate of $\lambda_{t} \rho_{1}$ is unbiased even in the presence of the measurement error in the dependent variable. However, Haider and Solon (2006) showed that $\lambda_{t}$ varies over a life cycle, which needs not equal to one, and the estimator is biased by a factor of $\lambda_{t}$. Also, see Solon (1992) for the attenuation bias when there is a classical measurement error in both the son's and the father's earnings.

${ }^{6}$ I impute fathers' missing earnings due to data availability, but the issue of measurement error by using current earnings for long-run earnings is incidental.

${ }^{7}$ This two-sample approach is sometimes incorrectly labeled as TS2SLS. However, it is not because not all exogenous second-stage regressors including the son's age variables are included in the first stage in the Eq. (4).

${ }^{8}$ In addition, Nybom and Stuhler (2016) provided examples when the unobserved idiosyncratic deviations from average income profiles might correlate within families or with family incomes, i.e., $\operatorname{Cov}\left(x_{i t}, v_{i t}\right) \neq 0$. For example, sons with high-income fathers might acquire more education and have lower initial earnings and steeper slopes of earnings profiles. Thus, the income trajectories of sons from rich and poor families could be different even if individual characteristics are controlled for.

${ }^{9}$ Note that $\rho_{1}$ in Eq. (3) will not be equal to $\rho_{1}$ in Eq. (5) as composite errors differ except for $x_{i}=\hat{x}_{i}$. One feasible expectation of the magnitude of $\rho_{1}$ is that $\rho_{1}$ in Eq. (5) would be larger than that in Eq. (3) if there is a positive correlation between fathers' sociodemographic variables and sons' economic status variable; Björklund and Jäntti (1997) and Ueda (2013) used it as an upper bound on the true estimates. Except for fathers' education, however, it is not clear how other fathers' industry or occupation variables can affect sons' earnings. Moreover, the direction of bias is even more questionable when lifecycle bias comes into consideration. Thus, in this study, I do not interpret $\hat{\rho}_{1}$ in Eq. (5) as an upper bound of $\hat{\rho}_{1}$ in Eq. (3). Hereafter, the value of $\rho_{1}$ is denoted as $\rho_{1}$ in Eq. (5).

${ }^{10}$ Results indicate that the elasticity estimate is robust to the treatment on the selfemployed workers.

${ }^{11}$ See Björklund and Jäntti (2009) for more discussion on different income measures and their features.

${ }^{12}$ For instance, Björklund and Jäntti (1997) used fathers' education and occupation, Nicoletti and Ermisch (2008) used occupational prestige and education, and Lefranc (2011) used education.

${ }^{13}$ Using the average age difference between fathers and sons from the national census, the potential fathers' age range in 1985 is set to $35-50$ when the sons were 14, which covers around $95 \%$ of the father-son pairs. Appendix: Table 6 demonstrates age differences between fathers and sons, and it is clear that statistics for KLIPS 2005 and National Census 2005 are closely similar; this can be verified easily in Appendix: Figure 1. This evidence justifies the use of KLIPS 2008 as a representative sample and restriction of samples based on the age information from KLIPS 2008.

${ }^{14}$ In fact, for sons 35-50 in 2008, their possible fathers were 34-68 in 1985; this covers $95 \%$ of fathers based on age difference information from census data in 2005. If I match the age range of 35-50 for fathers in 1985, I lose $20 \%$ of the sample; however, the estimates are similar. More information is provided in the next section.

${ }^{15}$ Between household head and non-head sons, differences exist in earnings and educational attainment. But excluding non-heads and restricting only to heads could be an 
endogenous selection. Moreover, there is no formal requirement to answer as a head but it is who represents the household. Thus, I included all male workers and presented the results for both samples. In addition, the national unemployment rate in Korea is around $5 \%$ in late 1980 s and around $3.5 \%$ in 2000 s, indicating that the excluded unemployed population is not troublesome.

${ }^{16}$ Note that estimates of age controls such as age and age squared of fathers are not used to generate fathers' missing earnings. This is because I am not predicting earnings at a particular age but am trying to predict fathers' long-run earnings, which requires the standardization on ages.

${ }^{17}$ First, I draw a bootstrap sample of fathers from KLIPS 2003 and run equation (4) to estimate parameters. Then I draw another bootstrap sample of sons from KLIPS 2006, from whose recollections data is used to generate fathers' earnings. I estimate $\rho_{1}$ in Eq. (5) and save estimates for 1000 replications. Murphy and Topel (1985) and Pagan (1984) showed that standard two-step procedures not accounting for generated regressor problems underestimate standard errors of the consistent second-step estimators and that corrected standard errors are larger than their uncorrected counterparts. If a researcher ignores the fact that fathers' earnings are generated and uses a bootstrap only in the second step, then standard errors are smaller than our approach, bootstrapping both steps, but still larger than those without bootstrapping in OLS.

${ }^{18}$ Key father's earnings predictors are chosen to maximize $R^{2}$ of the first-stage regression, and the results are summarized in Table 4 . The adjusted $R^{2}$ in the first stage, 0.393, is relatively larger than the other studies in Table 5: Piraino (2007) with 0.322, Mocetti (2007) with 0.301, Nicoletti and Ermisch (2008) with 0.289, and Ueda (2013) with 0.23. Preferred first-step regression results are summarized in Appendix: Table 7 with an age range of 35-50 for both generations using all three earnings predictors.

${ }^{19}$ If I match the age range of $34-68$ for potential fathers in 1985 covering $95 \%$ of the father-son pairs, the estimate is 0.397 , very similar to the estimate in the baseline model. Thus, hereafter, the age range of fathers in 1985 is fixed at 35-50 instead of 34-68. When self-employed sons are excluded, the sample size decreases to 502, and the estimate is 0.409 (0.064). Further analysis shows that the estimate is robust to the treatment on the self-employed workers. Results are available upon request. In addition, for household heads, the sample size is 572 and $\hat{\rho}_{1}$ is $0.351(0.062)$. Heads earn approximately 15 to $30 \%$ more than non-head members, and this might result in a relatively lower estimate.

${ }^{20}$ If I exclude the agriculture sector in industry and in occupation categories, which mostly considers the sample residing in urban areas, the estimate is 0.337 , the lowest among all models. It is reasonable to conjecture that the intergenerational mobility is higher in urban areas than in rural areas, accounting for job opportunities in those areas.

${ }^{21}$ Key comparable countries in Table 5 have different age ranges for fathers and sons and different sets of fathers' earnings predictors. Since each country has a different education-, industry-, and occupation structure and history and different worker quality, precise international comparison is more challenged, and no formal statistical test exists for comparison. For simplicity, when I match age ranges and sets of predictors with corresponding countries in Table 5, except for Chile where fathers' age-range information is unavailable, the relative mobility in Korea stay stable. 
${ }^{22}$ Hertz et al. (2008) documented the international comparison of educational inheritance for sons 20-69. Some noticeable countries in Table 5 are Brazil (0.59), Chile (0.6), China (rural, 0.2), Italy (0.54), Sweden (0.4), UK (0.31), and USA (0.46).

${ }^{23}$ Real GDP per capita in Korea increased more than three times between 1985 and 2003, implying that the potential fathers' cohort in 1985, which is more proximal to actual fathers, is different from the cohorts in 2003.

${ }^{24}$ (a) $D_{0} \equiv \operatorname{plim}_{n \rightarrow \infty} N^{-1} \sum_{i=1}^{N} \hat{x}_{i}^{\prime} \hat{x}_{i}=\mathbb{E}\left(x^{\prime} x\right)$, (b) $f(\cdot)$ is twice continuously differentiable in $\theta$ for each $x_{1}$ with the sample second moments of $\partial f / \partial \theta$ uniformly bounded in the sense of $\operatorname{plim}_{n \rightarrow \infty}\left(N^{-1} \sum_{i=1}^{N} \hat{x}_{i}^{\prime} \hat{x}_{i}\right)\left[N^{-1} \sum_{i=1}^{N} \nabla_{\theta} f\left(x_{1}, \theta\right) \xi_{i}\right]=D_{1}$, where $\nabla_{\theta} f\left(x_{1}, \theta\right)$ is the $K \times Q$ Jacobian of $f\left(x_{1}, \theta\right)^{\prime}$, and (c) $\hat{\theta}$ is a consistent estimator of $\theta$.

${ }^{25}$ See chapters 6 and 12 in Wooldridge (2010) for details.

\section{Appendix}

I derive the consistency of OLS estimator $\widehat{\rho_{1}}$ in Eq. (7), where the dependent variable has a measurement error due to using the proxy and the independent variable is generated from an auxiliary regression.

$$
y_{i t}=\rho_{1} \hat{x}_{i}+\omega_{i t}
$$

where $\omega_{i t}$ is equal to $\lambda_{t} \epsilon_{i}+v_{i t}+\lambda_{t} \rho_{0}+h\left(\right.$ Age $\left._{i t}\right)+\left(\lambda_{t}-1\right) \rho_{1} \hat{x}_{i}+\lambda_{t} \rho_{1}\left(x_{i}-\hat{x}_{i}\right)$.

Write Eq. (1) as

$$
y=x \rho+u
$$

where $x=f\left(x_{1}, \theta\right), x_{1}$ is a vector of variables from the first step that determines the unobservables, $f(\cdot)$, which is a $1 \times K$ vector of functions determined by the unknown vector $\theta$, which is $Q \times 1$. Assume that $\mathbb{E}\left(u \mid x_{1}\right)=0$ and errors are independent across observations. Further assume that $\hat{\theta}$ is a $\sqrt{N}$-consistent estimator of $\theta$. Now let $\hat{\rho}$ be the OLS estimator from the equation

$$
y_{i}=\hat{x}_{i} \rho+\text { error }_{i}
$$

where $\hat{x}_{i}=f\left(x_{1 i}, \hat{\theta}\right)$ and error ${ }_{i}=u_{i}+\left(x_{i}-\hat{x}_{i}\right) \rho$, the ordinary least squares estimator is

$$
\hat{\rho}=\left(\sum_{i=1}^{N} \hat{x}_{i}^{\prime} \hat{x}_{i}\right)^{-1}\left(\sum_{i=1}^{N} \hat{x}_{i}^{\prime} y_{i}\right)
$$

Write $y_{i}=\hat{x}_{i} \rho+\left(x_{i}-\hat{x}_{i}\right) \rho+u_{i}$, where $x_{i}=f\left(x_{1 i}, \theta\right)$, then plugging this in and multiplying through by $\sqrt{N}$ gives 


$$
\sqrt{N}\left(\hat{\rho}-\lambda_{t} \rho\right)=\left(N^{-1} \sum_{i=1}^{N} \hat{x}_{i}^{\prime} \hat{x}_{i}\right)^{-1}\left\{N^{-1 / 2} \sum_{i=1}^{N} \hat{x}_{i}^{\prime}\left[\left(x_{i}-\hat{x}_{i}\right) \lambda_{t} \rho+\xi_{i}\right]\right\}
$$

where $\xi_{i}=\lambda_{t} \epsilon_{i}+v_{i t}+\lambda_{t} \rho_{0}+h\left(\mathrm{Age}_{i t}\right)$.

Under the regularity condition stated in theorem 1 in Murphy and Topel (1985) or theorem 12.3 in Wooldridge (2010), ${ }^{24}$ a mean value expansion of $\hat{\theta}$ gives

$$
N^{-1 / 2} \sum_{i=1}^{N} \hat{x}_{i}^{\prime} \xi_{i}=N^{-1 / 2} \sum_{i=1}^{N} x_{i}^{\prime} \xi_{i}+\left[N^{-1} \sum_{i=1}^{N} \nabla_{\theta} f\left(x_{1}, \theta\right)^{\prime} \xi_{i}\right] \sqrt{N}(\hat{\theta}-\theta)+o_{p}(1)
$$

Because $\mathbb{E}\left(\nabla_{\theta} f\left(x_{1}, \theta\right)^{\prime} \xi_{i}\right)=0$, it follows that $N^{-1} \sum_{i=1}^{N} \nabla_{\theta} f\left(x_{1}, \theta\right)^{\prime} \xi_{i}=o_{p}(1)$, and since $\sqrt{N}(\hat{\theta}-\theta)=O_{p}(1)$,

$$
N^{-1 / 2} \sum_{i=1}^{N} \hat{x}_{i}^{\prime} \xi_{i}=N^{-1 / 2} \sum_{i=1}^{N} x_{i}^{\prime} \xi_{i}+o_{p}(1)
$$

Using similar reasoning, by mean value expansion

$$
N^{-1 / 2} \sum_{i=1}^{N} \hat{x}_{i}^{\prime}\left(x_{i}-\hat{x}_{i}\right) \lambda_{t} \rho=-\left[N^{-1} \sum_{i=1}^{N}\left(\rho \otimes x_{i}\right)^{\prime} \nabla_{\theta} f\left(x_{1}, \theta\right)\right] \sqrt{N}(\hat{\theta}-\theta)+o_{p}(1)
$$

Now assume that

$$
\sqrt{N}(\hat{\theta}-\theta)=N^{-1 / 2} \sum_{i=1}^{N} r_{i}(\theta)+o_{p}(1)
$$

where I assume $\mathbb{E}\left[r_{i}(\theta)\right]=0$, which even holds for most estimators in nonlinear models. ${ }^{25}$ If I assume that $\operatorname{Cov}\left(x_{i}, h\left(\mathrm{Age}_{i t}\right)\right)=0$, then

$$
\operatorname{plim}_{n \rightarrow \infty} \hat{\rho}=\frac{\lambda_{t} \rho \operatorname{Var}\left(x_{i}\right)+\operatorname{Cov}\left(x_{i}, v_{i t}\right)}{\operatorname{Var}\left(x_{i}\right)}
$$

which reduces to $\lambda_{t} \rho$ if $\operatorname{Cov}\left(x_{i}, v_{i t}\right)=0$. For consistency, replacing $x_{i}$ with $\hat{x}_{i}$ in an OLS estimation causes no problem as in Wooldridge (2010). 
Table 6 Father-son age difference

\begin{tabular}{lllll}
\hline & Census 2005 & KLIPS 2005 & KLIPS 2006 & KLIPS 2008 \\
\hline Observation & 139,832 & 2654 & 2655 & 2564 \\
Average age difference & 30.54 & 29.79 & 29.74 & 29.79 \\
Standard deviation & 4.25 & 4.25 & 4.22 & 4.21 \\
Age range for 90\% of observation & $24-39$ & $23-37$ & $23-37$ & $23-37$ \\
Age range for 95\% of observation & $22-41$ & $22-39$ & $22-39$ & $22-39$ \\
\hline
\end{tabular}

\section{a}

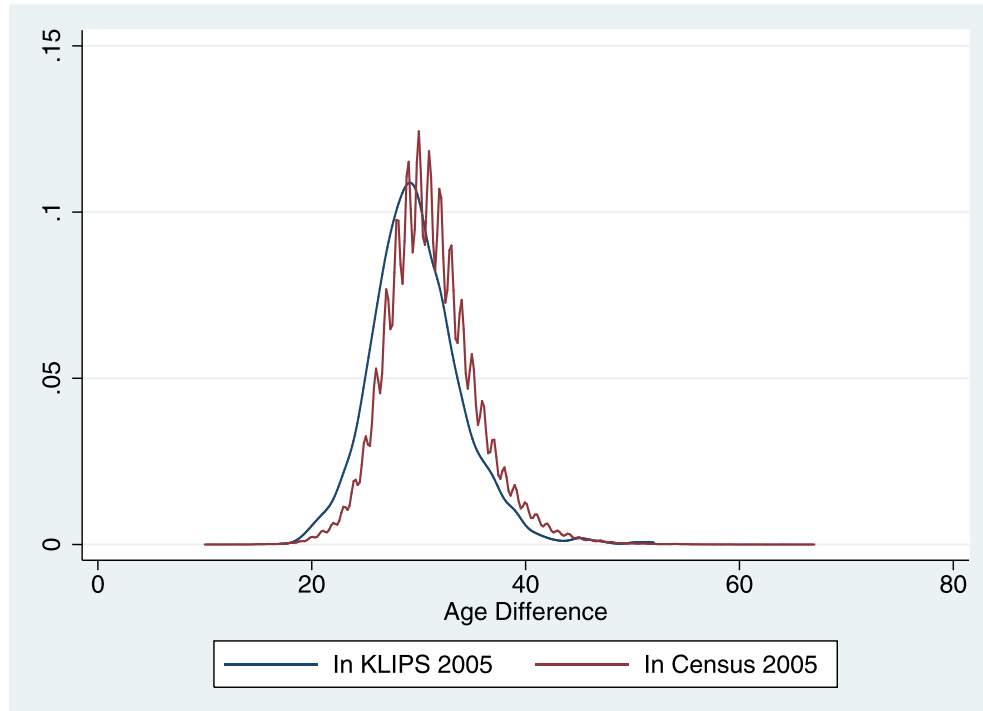

b

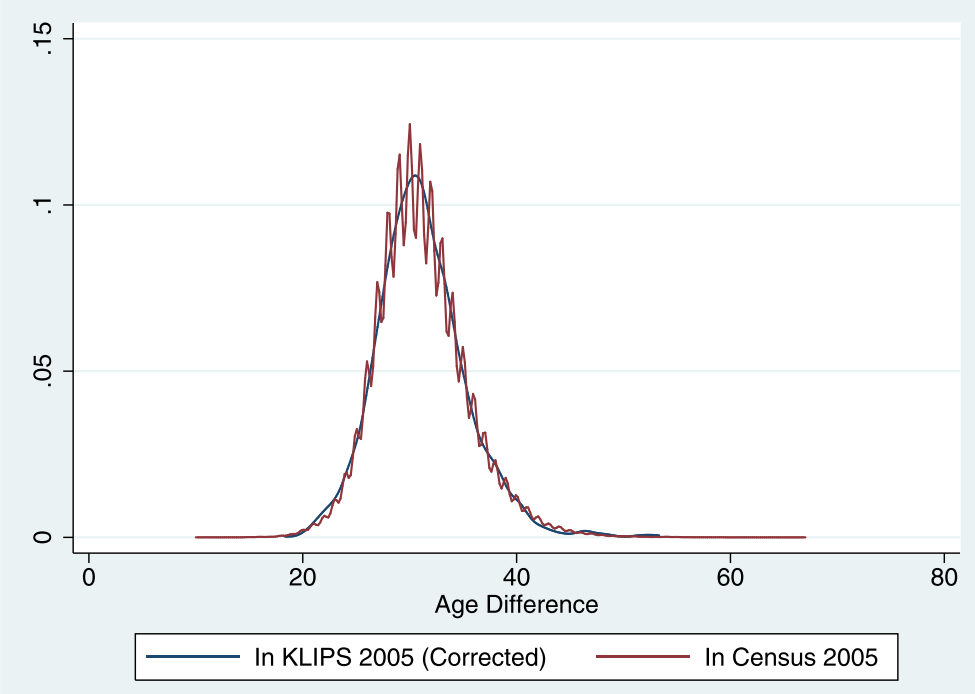

Fig. 1 Average age difference between fathers and sons in KLIPS 2005 and Census 2005. a Average age difference in the original samples. b Average age difference when the difference between KLIPS 2005 and Census 2005 is corrected 
Table 7 First-step regression

\begin{tabular}{|c|c|c|}
\hline \multicolumn{3}{|l|}{ Dependent variable: log father's earnings } \\
\hline & Coefficient & Std. err \\
\hline \multicolumn{3}{|l|}{ Education } \\
\hline None & Omitted dummy & \\
\hline Elementary & 0.2164 & 0.1032 \\
\hline Middle & 0.3199 & 0.0999 \\
\hline High & 0.4578 & 0.1006 \\
\hline Community college (2 years) & 0.7388 & 0.1230 \\
\hline University (4 years) & 0.7712 & 0.1043 \\
\hline Graduate school & 0.7910 & 0.1313 \\
\hline \multicolumn{3}{|l|}{ Occupation } \\
\hline Professional, technical, managerial & 0.0735 & 0.1301 \\
\hline Administrative and government officer, entrepreneur & 0.0315 & 0.1923 \\
\hline Clerical worker & 0.1172 & 0.1247 \\
\hline Sales worker & 0.3916 & 0.1272 \\
\hline Service worker & 0.3992 & 0.1415 \\
\hline Production worker & 0.3119 & 0.1243 \\
\hline Agriculture, fishing, forestry & Omitted dummy & \\
\hline \multicolumn{3}{|l|}{ Industry } \\
\hline Agriculture, fishing, forestry & Omitted Dummy & \\
\hline Mining & 0.2536 & 0.1711 \\
\hline Manufacturing & 0.4053 & 0.1452 \\
\hline Utilities & 0.4392 & 0.1933 \\
\hline Construction & 0.1701 & 0.1486 \\
\hline Wholesale and retail trade & 0.3348 & 0.1503 \\
\hline Communication, transportation & 0.3703 & 0.1478 \\
\hline Banking, insurance, business service & 0.3956 & 0.1547 \\
\hline Community, social, and personal services & 0.3885 & 0.1445 \\
\hline
\end{tabular}

Note: Age of the father-son sample is restricted to $35-50$

\section{Acknowledgements}

I would like to thank Gary Solon, Steven Haider, and Chris Ahlin for helpful comments and sharing their insights. I am also grateful for comments and suggestions from seminar participants at the Canadian Economics Association, Midwest Economics Association, and Michigan State University.

I would also like to thank the anonymous referee and the editor for the useful remarks.

Responsible editor: David Lam

\section{Competing interests}

The IZA Journal of Development and Migration is committed to the IZA Guiding Principles of Research Integrity. The author declares that he has observed these principles.

\section{Publisher's Note}

Springer Nature remains neutral with regard to jurisdictional claims in published maps and institutional affiliations.

Received: 11 May 2017 Accepted: 23 May 2017

Published online: 06 December 2017

\section{References}

Björklund A, Jäntti M. Intergenerational income mobility and the role of family background. In: Oxford Handbook of Economic Inequality. Oxford: Oxford University Press. 2009. p. 491-521.

Björklund A, Jäntti M. Intergenerational income mobility in Sweden compared to the United States. Am Econ Rev. 1997;87(5):1009-18.

Black SE, Devereux P. Recent developments in intergenerational mobility. Handb Labor Econ. 2010.

Blanden J, Haveman R, Smeeding T, Wilson K. Intergenerational mobility in the United States and Great Britain: A comparative study of parent-child pathways. Rev Income Wealth. 2014;60(3):425-49.

Böhlmark A, Lindquist MJ. Life-cycle variations in the association between current and lifetime income: replication and extension for Sweden. J Labor Econ. 2006;24(4):879-96. 
Bowles S, Gintis H. The inheritance of inequality. J Econ Perspect. 2002;16(3):3-30.

Brenner J. Life-cycle variations in the association between current and lifetime earnings: evidence for German natives and guest workers. Labour Econ. 2010;17(2):392-406.

Cervini-Plá M. Exploring the sources of earnings transmission in Spain. Hacienda pública española. 2013:45-66.

Choi J, Hong GS. An analysis of intergenerational earnings mobility in Korea: father-son correlation in labor earnings. Korean Soc Secur Stud. 2011;27(3):143-63.

Dunn CE. The intergenerational transmission of lifetime earnings: evidence from Brazil. BE J Econ Anal Policy. 2007;7(2).

Fortin NM, Lefebvre S. Intergenerational income mobility in Canada. In: Labour Markets, Social Institutions, and the Future of Canada's Children. 1998. p. 89-553.

Francesconi M, Nicoletti C. Intergenerational mobility and sample selection in short panels. J Appl Econ. 2006;21(8): 1265-93.

Gong H, Leigh A, Meng X. Intergenerational income mobility in urban China. Rev Income Wealth. 2012;58(3):481-503. Grawe ND. Lifecycle bias in estimates of intergenerational earnings persistence. Labour Econ. 2006;13(5):551-70.

Haider S, Solon G. Life-cycle variation in the association between current and lifetime earnings. Am Econ Rev. 2006;96: 1308-20.

Hertz T, Jayasundera T, Piraino P, Selcuk S, Smith N, Verashchagina A. The inheritance of educational inequality: international comparisons and fifty-year trends. BE J Econ Anal Policy. 2008;7(2).

Kim H. An Analysis of intergenerational economic mobility in Korea. Korea Development Institute. 2009.

R of Korea. Ministry of Education: Educational development in Korea 1988-1990; 1991. Report for the International Bureau of Education, Geneva. Seoul: Korean National Commission for UNESCO.

Lefranc A. Educational expansion, earnings compression and changes in intergenerational economic mobility: Evidence from French cohorts. 20111931-1976. Unpublished manuscript, University of Cergy.

Lefranc A, Ojima F, Yoshida T. Intergenerational earnings mobility in Japan among sons and daughters: levels and trends. J Popul Econ. 2014;27(1):91-134.

Leigh A. Intergenerational mobility in Australia. BE J Econ Anal Policy. 2007;7(2).

Mocetti S. Intergenerational earnings mobility in Italy. BE J Econ Anal Policy. 2007;7(2).

Murphy KM, Topel RH. Estimation and inference in two-step econometric models. J Bus Econ Stat. 1985;3:370-9.

Nicoletti C, Ermisch J. Intergenerational earnings mobility: changes across cohorts in Britain. BE J Econ Anal Policy. $2008 ; 7(2)$.

Núñez J, Miranda L. Intergenerational income and educational mobility in urban Chile. Estud Econ. 2011;38(1):196-221.

Nybom M, Stuhler J. Heterogeneous income profiles and lifecycle bias in intergenerational mobility estimation. J Hum Resour. 2016;51(1):239.

Pagan A. Econometric issues in the analysis of regressions with generated regressors. Int Econ Rev. 1984;25:221-47.

Piraino P. Comparable estimates of intergenerational income mobility in Italy. BE J Econ Anal Policy. 2007;7(2).

Solon G. Cross-country differences in intergenerational earnings mobility. J Econ Perspect. 2002;16:59-66.

Solon G. Intergenerational mobility in the labor market. Handb Labor Econ. 1999.

Solon G. Intergenerational income mobility in the United States. Am Econ Rev. 1992;82:393-408.

Ueda A. Intergenerational mobility of earnings in South Korea. J Asian Econ. 2013:1-22.

Ueda A, Sun F. Intergenerational economic mobility in Taiwan: Waseda University Working Paper; 2012.

Wooldridge J. Econometric analysis of cross section and panel data: MIT Press; 2010.

\section{Submit your manuscript to a SpringerOpen ${ }^{\circ}$ journal and benefit from:}

- Convenient online submission

- Rigorous peer review

Open access: articles freely available online

- High visibility within the field

- Retaining the copyright to your article

Submit your next manuscript at $\gg$ springeropen.com 